\title{
The Power of Creative Learning through the Arts: Economic Imperative or Social Good?
}

\author{
Author
}

\author{
Alex Southern \\ Yr Athrofa: Institute of Education \\ University of Wales Trinity Saint David \\ Dylan Thomas Centre, Swansea, SA11RR \\ Email: a.southern@uwtsd.ac.uk
}

\section{Abstract}

This article uses data generated through qualitative methods and discourse analysis to explore how 'creative learning' is articulated in the current educational context in Wales. The research focused on the Arts and Wellbeing in Education (AWE) professional learning programme for primary and secondary schools, delivered by 'Arts Champions'

through one of the Regional Arts and Education Networks. The Networks were created to support the Welsh Government / Arts Council Wales Creative Learning through the Arts Action Plan (Welsh Government, 2015). The analysis applies a poststructural framework, influenced by the work of Foucault, to examine the circulating discourses around the 'benefits' and 'value' of creative learning, and the arts. The discussion reveals the underlying structures and ideological project that in/form the policy context, and the resultant practice. The findings describe how the Welsh Government rhetoric describes a broadly democratic, economic value of the arts, while the case study Network D emphasises the benefit of the arts as a 'social good'. Within this context, AWE functions as a local revolution extending, enhancing and personalising the 'social good' so that the benefits centre on wellbeing through mindful approaches to creativity, the value of which is decided by the individual.

\section{Keywords}

Arts education, Creative Learning through the Arts, Welsh Government, curriculum, professional learning, wellbeing

Submitted 1 October 2018

Accepted 7 March 2019 


\section{Arts in Education in the Schools of Wales}

The education system in Wales is undergoing a radical overhaul that will see changes to the curriculum, to pedagogy, to how both pupils and teachers learn, and to how their achievements/learning is assessed. In September 2017, the Cabinet Minister for Education announced a new, National Mission to raise standards in schools. The plan to achieve this mission includes Initial Teacher Education reform and the creation of new professional standards, and the establishment of a national approach to continual, longterm career development for teachers (Welsh Government, 2017). Alongside these reforms are changes to the statutory curriculum for pupils aged 3-16. Following publication of Successful Futures (Donaldson, 2015) the 'Donaldson Review' of the curriculum, the Welsh Government is implementing a period of research and development that engages and draws on the expertise of a broad range of stakeholders. The final version of the new curriculum will be circulated to schools for implementation across Wales from 2022. The new curriculum will be organised into six Areas of Learning and Experience (AoLE) as recommended by Donaldson (2015). The six AoLEs are, in alphabetical order, Expressive Arts; Health and Well-being; Humanities; Languages, Literacy and Communication; Mathematics and Numeracy; and Science and Technology. The aim of this curriculum model is to break down traditional subject boundaries and allow greater emphasis on learner-centred, cross-curricular working. Of particular note is the inclusion of the Expressive Arts as a distinct AoLE, alongside the more 'traditional' subject groupings that characterised the version of the National Curriculum introduced in the UK from 1988 (Carr and Hartnett, 1996), and in direct contrast to recent concerns about the decline of the arts in the curriculum in England (see 
for example, Cultural Learning Alliance, 2017; Jeffries, 2018). This recognition of the Expressive Arts draws on the findings of research published by Professor Dai Smith in 2013, and runs counter to the curricula of many nations globally (see, for example:

EACEA, 2009; Henley, 2012; Wagner, 2006). Smith's (2013) report, Arts in Education in the Schools of Wales, responds to the Welsh Government call for an examination of schools' involvement in the arts; of arts education in a Welsh context; the identification of good practice, barriers, inclusion, and whole-school approaches; and recommendations for joint working across the arts and education sectors to enable development of creative skills (Smith, 2013). The report details the consultation process with education, and arts practitioners, as well as pupils and other stakeholders across Wales, and makes a series of recommendations regarding the development of arts education and its perceived 'value' to learning. Within the 12 recommendations, all of which were accepted, are proposals for Welsh Government to support the creation of schools' "arts champions", the establishment of "Creative Learning Networks" to encourage the exchange of information and ideas, and work with Professional Learning Communities to "improve standards of creative learning in schools" (Smith, 2013: 4). The Welsh Government responded positively to the report, and has developed a five year plan, delivered in partnership with Arts Council of Wales, based on the recommendations. The plan is entitled, Creative Learning through the Arts - an action plan for Wales (Welsh Government, 2015). The three central aims of which are to: "improve attainment through creativity; increase and improve arts experiences and opportunities in schools; support our teachers and arts practitioners in developing their skills" (Welsh Government, 2015: 4). 
At the time of writing, these aims are being addressed through a number of distinct, yet overlapping programmes, engaging schools and arts practitioners in Wales. One such programme is the Regional Arts Education Networks, which broadly aim to "increase and improve arts experiences and opportunities in schools" (Network D internal document, 2016). The Networks cover the same geographical regions as the four regional consortia, which combine and coordinate local education authority responsibilities in each region of Wales. The consortia are: Central South Consortium Joint Education Service (CSCJES), Education Achievement Service (EAS, serving South East Wales), Education through Regional Working (ERW, covering Mid and West Wales) and Regional School Effectiveness \& Improvement Service (GwE, North Wales). This activity, and the planned future development of the programmes, demonstrate a level of commitment from Welsh Government in supporting and encouraging the arts and creative learning within the curriculum, and a practice-led response to Arts in Education in the Schools of Wales (Smith, 2013).

\section{The Educational 'Benefits' of the Arts}

Both Smith (2013) and Donaldson (2014) make recommendations for a new framework for arts-related professional learning (PL) to address the lack of relevant and cohesive learning opportunities for teachers and arts practitioners alike. This lack was also noted by the national inspectorate, Estyn, in the published guidelines, Best Practice in Teaching and Learning in the Arts at KS2 (Estyn, 2015), and in the Welsh Government response to Smith's report (Welsh Government, 2013). The absence of training opportunities in both 
Initial Teacher Education (ITE) and in-service PL relevant to arts education is not exclusive to Wales, and has been identified through research in other countries. Improved teacher training was called for in the 'Henley Report', Cultural Education in England (Henley, 2012), and has been found lacking across Europe, North America, and Asia-Pacific countries, as well as Latin America and the Caribbean (Wagner, 2006). This lack refers not only to provision, but to an absence of 'quality' in the opportunities provided, and has been attributed to a range of factors (Wagner, 2006). One such factor is the need for cohesive strategy and policy. Across European countries, cohesion has been inhibited by the shared responsibility for arts education between two or more government departments (Henley, 2012; Wagner, 2006; EACEA, 2009). Arts education has also previously been side-lined, and included only within other, compulsory curriculum subjects. For example, in the UK, Dance is frequently taught/learned within Physical Education, and Creative Writing and Drama within English/Welsh. Furthermore, research across 30 European countries found there is a hierarchy in the curriculum, whereby reading, writing and numeracy are prioritised (EACEA, 2009). The same has been found in Australia, where literacy and numeracy exist at the top of the hierarchy, with the arts and humanities at the bottom (Ewing, 2010). Both research projects also found that there exists a hierarchy within the arts, so that visual arts and music are prioritised over other art forms (EACEA, 2009; Ewing, 2010). These hierarchies, along with a rigid curriculum structure, have meant that arts education in the UK, and particularly professional learning in arts education, have been overlooked in favour of the more 'pressing' educational needs of literacy and numeracy. There is some evidence to suggest that learning in the arts and creativity may contribute to improvements in literacy and numeracy, such as the 
US study that claims "reading and language skills" as well as "mathematics skills" as outcomes of enrolment in arts courses (Ruppert, 2006). However, these claims are outweighed by alternative research that suggests there simply is not enough evidence to support such findings. The National Foundation for Educational Research (NFER) carried out in-depth case studies and secondary data analysis of pupil surveys and found no evidence that learning in the arts increased academic performance at GCSE (Harland et al, 2000). Further studies carried out in the UK, Australia, Asia, and Asia-Pacific countries have pointed to wider personal and social outcomes for pupils resulting from arts education. For example, a greater appreciation of cultural diversity, community cohesion, a positive impact on whole school ethos, creativity, and thinking skills (Ewing, 2010; Harland et al, 2000; Wagner, 2006). However, an investigation into 90 international research and evaluation studies of arts and cultural practice, sponsored by Arts Council England, found no causal links between arts/culture and wider societal impact (Mowlah et el, 2014).

Overlooked in much of the above discussion of the potential educational benefits, is the development of arts-based skills in and of themselves, and the place of those skills within the school curriculum - and in wider society/culture. Fleming (2011) explores the history of the arts in Western societies in order to expand upon the apparent dichotomy of learning in and learning through the arts, and the impact on their perceived benefits. The author argues that the concept of learning through the arts is more democratic in nature, and has the closest associations with contemporary practice. Whereas, learning in the arts has been more focused on the intrinsic benefits of the disciplines, and therefore 
associated with traditionalist standpoints, for example the 'art for art's sake' movement of the $19^{\text {th }}$ Century (Fleming, 2011). Taken to its extreme articulation, this argument ends in an elitist, 'high art', perspective that removes any benefits of the arts from their realworld setting. By contrast, Fleming (2011) argues, learning through the arts considers the wider social and, in the case of formal education, cross-curricular, benefits of the arts, and the ways in which the potential learning outcomes are generated. For example, connections between drama and theatre education, and historical, cultural understandings which may, in turn, enable development of personal and social skills. Of course, it must be recognised that the two approaches are rarely taken to their extreme conceptualisations, and Fleming (2011) does acknowledge that each approach can comprise the outcomes, or benefits, usually associated with the other. The historical discussion of this apparent dichotomy is relevant to current debates. Research reports, globally, have made a range of claims for the value of the arts and creativity to statutory education. It has been argued that the arts contribute to developing skills and knowledge in specific curriculum subjects or skills such as literacy and numeracy; improving levels of attainment/achievement; wider social benefits such as confidence levels and communication; to industry; to the development of artistic skills or 'habits of mind'; and to industry (see for e.g. Cultural Learning Alliance, 2011; Ewing, 2010; Mowlah et al, 2014; Spencer et al, 2012; Wagner, 2006; Winner et al, 2013). There has also been discussion surrounding whether there is enough evidence to make any claims linking the arts to wider curriculum skills (Harland et al, 2000). Each of these rhetorical positions demonstrates a claim to the 'value' of the arts, and creativity more broadly. The value is grounded in the reality of the context of the research and can be claimed against 
demonstrable evidence that shows improvements in literacy, or the enhancement of pupils' team-working skills, or chances of employment, for example. Far from demonstrating a lack of consensus, this divergence of opinion actually highlights the breadth of multifarious benefits that have been identified in a range of contexts, and with a variety of objectives.

\section{Research Question and Methodology}

This article explores how 'creative learning' is articulated in the current educational context in Wales, focusing on one of the Regional Arts and Education Networks as a case study, in order to answer the following research question: how are the benefits of Creative Learning through the Arts (Welsh Government, 2015) articulated through a case study Regional Arts and Education Network? The dataset was generated between December 2017 and May 2018, and comprises three distinct research activities. The first comprises an ascending model of discourse analysis (from Foucault, 1980), applied to Creative Learning through the Arts (Welsh Government, 2015); to documents relating to the formation and purpose of the case study Network; and materials made available via the Network's website and through the mail shot to its members. The analysis explores the relations between organisations, individuals, and practices, to reveal the underlying structures that form the context, and give an indication of the ideological project informing and communicated through the Welsh Government's action plan, and the resultant practice (from Foucault, 2002a; 2002b). The resultant narrative traces the philosophical, social, and political currency of the programme, and the effect/s on the 
perceived or implied benefits/value of creative learning through the arts. Secondly, I interviewed two Arts Champions, jointly, on two separate occasions. The interviewees were part of a team of Arts Champions who had made the decision to work collaboratively to design and deliver a programme of PL for schools, which focused on supporting teachers' wellbeing, and which I describe in more detail later in this article. The interviews were semi-structured, audio-recorded, transcribed and coded for analysis, and lasted approximately one hour each. The first took place in January 2018 towards the beginning of the team's PL programme, and the second took place in May and comprised a reflection on activity and discussion of plans. Finally, I observed six workshop sessions delivered by the Arts Champions. The observations followed a semi-structured framework adapted from the work of Spradley (1980), and LeCompte and Preissle (1993), and a reflection process adapted from Bogdan and Biklen (1992). The methodology enabled me to research the circulating discourse within the specific contexts of the schools, while participating in the creative workshops. The data generated through this methodology is unavoidably subjective, due to the necessarily retroactive production of my observation notes. This is acknowledged both in this article, and in the notes themselves, since the reflection process incorporated information on the methods of observation.

\section{The Benefits of Creative Learning through the Arts}

In 1999, the report from the National Advisory Committee on Creative and Cultural Education, All Our Futures (NACCCE, 1999) argued for a national, UK-wide, strategy that enables young people up to the age of 16 to engage in cultural and creative 
education. The report promotes the concept of creativity for social good, a democratic approach to 'using' the arts, whereby creativity is only valuable insofar as it contributes to the final outcome, such as excluded youths placed back in the education system. The rhetoric of All Our Futures (NACCCE, 1999) also implies that creativity would be most productive if aligned with the business world, and that association persists today. This theoretical standpoint is representative of the political landscape at the time of the document's publication. 'New' Labour were in power in the UK, and had made the arts and creativity key elements of the party's social policy agenda (Belfiore, 2011). This historical alignment between creativity and the economy is mirrored in the recent report from the Warwick Commission (2015) that links the 'creative industries' to the UK economy, and the country's global influence, in order to highlight the current lack of investment in supporting the arts. It can also be seen across the European Union, as indicated by the EU Year of Creativity and Innovation in 2009 that made direct links between creativity and industry in the pursuit of revenue (Drotner, 2011). Creative Learning Through the Arts (Welsh Government, 2015) includes a number of key concepts that recur throughout the literature on the arts, creativity, and creative learning, one of which is the link between the economy and the arts. The following analysis of the document offers an insight into how the Welsh Government and Arts Council of Wales conceptualise the benefits and 'value' of the arts to learning.

The Ministerial Foreword, written by then Minister for Education, Huw Lewis, and Deputy Minister for Culture, Sport and Tourism, Ken Skates, draws direct links between the arts, culture, creative skills, the curriculum, and the economy: 
"only through having high quality arts and creative experiences in

schools, by valuing them and giving them their deserved place in our

curriculum, by making them available to all children, especially those

from deprived backgrounds, that we can nurture the potential of our

learners and develop skills we need for our economy." (Welsh

Government, 2015: 3)

The rhetoric mimics the political landscape of Tony Blair's New Labour of the late 1990s and early 2000s, by ascribing an economic value to creativity, made possible via the education system. The statement combines a number of conceptualisations of the benefits and value of the arts and creativity, including the specific reference to skills - grounding the creative in the real. However, it can be broadly characterised as advocating creativity for economic imperative (Banaji, 2011), in that it omits any further potential benefits of the arts (and culture, which remains undefined and is somewhat conflated throughout the document), and focuses on the ultimate aim of economic 'need'. However, further on in the document, the ideological positioning shifts to take on a greater social dimension. The key aspects of pupils' development that will represent progress in this context are improvements in literacy, numeracy, and "the creativity of learners" (Welsh Government, 2015: 17). The programme will also be evaluated in terms of its impact on 'closing the gap' between the attainment of pupils from socio-economically disadvantaged backgrounds and their peers. Improvements in literacy and numeracy, and closing the attainment gap are Welsh Government aims for the education system as a whole, as outlined in the 'National Mission' (Welsh Government, 2017). There is no indication as to how 'creativity' will be measured, but this statement represents a recognition of the 
potential benefits of the arts in and of themselves. In this respect, the plan advocates both learning in and learning about the arts, as outlined by Fleming (2011). The aim to provide opportunities for young people from disadvantaged backgrounds, moves the rationale and the benefits of the arts from the economic to the more democratic argument of "creativity for social good" (Banaji, 2011). These young people, in particular, "for whom active participation in the arts and working with creative practitioners can engage, motivate, build confidence and transferable skills" are assumed to benefit from a broad range of outcomes that the arts can engender (Welsh Government, 2015: 6). The implication here is that the benefits of the arts are transitional, with the central aim of taking (disadvantaged) young people from one place and delivering them elsewhere; they are tools to overcome disadvantage. The More Able and Talented (MAT) pupils are also singled out for attention in the action plan, as it is implied that the arts enable opportunities for extended learning, particularly in literacy. The action plan is targeted towards specific audience groups who are perceived as in particular need of the ascribed 'benefits' of creative learning, which are improvements in literacy, numeracy, and creativity. The result is that while democratic in term of its rhetorical stance towards creativity, Creative Learning through the Arts is not inclusive - it does not aim to engage all students in creative learning, only those for whom a pre-determined benefit has been identified.

The Welsh Government approach to claiming the benefits of creative learning can be understood with reference to Foucault's theories of discipline. Foucault describes discipline as a "technology of power" and argues that, contrary to popular assumption, 
power is not a repressive force (Foucault, 1991: 194). Instead, he argues, "power produces; it produces reality; it produces domains of objects and rituals of truth" (Foucault, 1991: 194). Discipline also produces what Foucault terms, docile bodies, "that may be subjected, used, transformed and improved" (Foucault, 1991: 136). Discipline objectifies the individual, categorising her/him according to externally-identified attributes, and turning her/his body to political purpose - i.e. it turns an aptitude into a capacity, a function, in response to a particular need. In the context of the Welsh Government's action plan, the discipline of the arts re-structures, re-trains the docile bodies of identified groups of pupils in order to make them economically useful. The pupils identified in Creative Learning through the Arts (Welsh Government, 2015) are either those from disadvantaged backgrounds who are eligible for free school meals (eFSM) or those who have been classified as More Able and Talented (MAT) than their peers. Within any disciplinary system, there are mechanisms that structure and determine law, identifying specific offences and maintaining forms of judgement. In the school, these mechanisms are governed by school rules, and by pedagogies that generate normative behaviours, actions, structures. For any 'offence', where these rules or pedagogies are broken or disrupted, there are consequences for the pupil. "A pupil's 'offence' is not only a minor infraction, but also an inability to carry out 'his tasks'" (Foucault, 1991: 179). In this context, pupils categorised as eFSM and MAT represent an inability to carry out the task of achieving to a pre-determined, required standard. In Foucault's words, these pupils need to be 'normalised'; brought to the required standards, through discipline - i.e. they could do better. The Foreword of Creative Learning through the Arts (Welsh Government, 2015) describes how arts and creative experiences must be 
given a valued place in the curriculum in order to "nurture the potential" of learners and develop skills "we need for our economy" (Welsh Government, 2015: 3). In this manner, Welsh Government and Arts Council of Wales claim authority over the curriculum, over pedagogies, and over pupils. The learners are objectified, their bodies turned to the purpose of developing skills to boost the economy. Creative Learning through the Arts (Welsh Government, 2015) can be understood as an object of discourse produced by political power as a means of asserting control over the curriculum, and employing the arts as a disciplinary technology that aims to normalise pupils to fulfil an economic imperative.

\section{The Benefits of the Arts across the Networks}

The four Regional Arts and Education Networks share the overall aims of connecting arts practitioners and teachers; delivering a programme of professional learning; and establishing a group of Arts Champions. There are variations in how each Network has translated these aims into practice that reflect the geographical, and educational contexts, as well as the personal choice of those coordinating the Networks. In addition, the Networks' activity would have been shaped to an extent by the requirements of the central funder and organisational distributor/host in each setting. The first, Network A, covers a predominantly urban area. Network A publishes an annual brochure of events and professional learning, and details of arts organisations and individuals in the area, for teachers to access. The events include conferences, termly networking events, and 'masterclasses' for teachers in specific art forms. For example, the 2017-18 brochure advertises a session on conducting, a Design for Performance event, and a spoken word 
and SLAM session. The role of the Arts Champions is described as working with ArtWorks Cymru - a partnership programme for participatory arts - to develop a PL session. The session, Expressive Arts Projects - Collaborating for Success, is closely linked to the aims of the new curriculum and has been offered to teachers over the 20172018 school year. Network A's website also points visitors to the Creative Learning Zone on the Welsh Government's online educational resource, Hwb. The emphasis of activity within Network A is on delivering tried and tested approaches for teachers to develop arts education within schools, in partnership with experienced professionals and organisations in the region, many of whom have national/international reach. Network B offers an information service and connections to expertise that is much more focused on responding to teachers' needs. The emphasis is on teachers contacting the Network should they require services, information, or are interested in inviting an Arts Champion into their school to run a project. The website includes profiles for all eight of the Arts Champions, which none of the other regions has publicised, and visitors are encouraged to contact Network B to find out about events, rather than advertising a pre-planned list of activities for the year. As with all the Networks, Network B makes a range of documents accessible, such as relevant policies, guides for teachers, and research reports, and all four Networks have social media profiles through which they share information on upcoming events, good news stories, and multimedia reports of activities in schools. Network $\mathrm{C}$ takes yet a different approach to delivering the Creative Learning through the Arts (Welsh Government, 2015) action plan. There are few resources on the website and the Arts Champions' role is described as advisory, supporting specific schools and teachers to share good practice and become more creative. The emphasis here is on a 
targeted approach to providing schools with training and support to meet identified needs, before building a bank of 'evidence' that describes good practice. Since the role of the Networks is, in part, to support teachers' professional learning, the main target audience of all four Networks is teachers, rather than pupils. The three Networks outlined above emphasise, to varying degrees, the cross-curricular benefits of the arts with some reference to arts-based skills in and of themselves. The fourth Network, D, adopts a slightly different approach, which can be identified through the information and resources with which audiences are provided.

\section{Case Study: Network D}

The overall aim of Network D is less focused on the development of skills than the other Networks, and there is no reference to any specific art forms. The approach is broad, and incorporates a range of elements and target audiences, but all activity is intended to support the creativity of teachers, through professional learning programmes. The website includes information on events and activities, the purpose of the Network and of Creative Learning through the Arts (Welsh Government, 2015), funding sources available through this initiative, a directory of artists, and a forum for practitioners who have signed up to the Network. There is also a page dedicated to resources that includes a range of practical, skills-based information; links to research reports or academic articles on the 'value' of creative learning, creativity and the arts to education; and two case study examples of school-based projects delivered by artists through the Network. Both examples include a professionally made video of workshops delivered in schools, cut with 'talking head' interviews with teachers, arts practitioners, and pupils involved in the 
projects. The video of Stretching the Literacy Skills of More Able and Talented Pupils functions as a positive testimonial, giving 'evidence' from both teachers and pupils of what they have enjoyed about the project, and in what areas they have improved. The tone of the video is not simply positive, as could be expected from a case study report, it also advocates for a specific role for creativity and creative practice as the 'norm'. The teacher interviewed states that she hopes teachers will "use creative practice in their classrooms as a matter of course", implying firstly that this isn't the case at present, and also that the benefits of creative practice in the classroom are essential. These benefits are described in terms of skills, attitudes, and behaviours, and are borne out in the evidence offered by pupils. While not disputing that these benefits were felt, the video functions more as an advertisement than evidence, since the interview questions are not heard by the audience, and the information, action, and opinion expressed are all necessarily selected through the filmmaking process. The benefits of creative learning advocated for here meet the aims of Creative Learning through the Arts (Welsh Government, 2015) explicitly. The video and pupil testimony tell us that More Able and Talented pupils engage in creative learning workshops and her/his literacy skills are improved as a result.

The other case study video, Changing Landscapes - Lead Creative Schools follows a similar structure in presenting a combination of live footage of the project in action, with talking heads during and after the project is complete, and reflective interviews with key participants. In a slight variation from the Stretching the Literacy video, Changing Landscapes includes footage of a project discussion meeting between school staff and the artists involved in running the project. This cinema vérité style, however brief, adds a 
level of additional realism to the otherwise expository documentary (Nichols, 2010). It enables us, the audience, to get a 'behind the scenes' look at how the project takes shape and the concerns and enthusiasms of the central agents. The approach is coercive and, when the artist states that she is pleased that a teacher feels that she, too, is going on the same journey of learning as the pupils, we are convinced of the possibilities for shared development that arts practice enables. The focus of discussion around the 'benefits' of the project in this context is on the impact on pupils' behaviour. This is expressed as pupils engaging in activities that are unexpected, 'out of the ordinary' for that individual. One example offered is of a female pupil who enjoyed getting dirty using mud to create pictures; something which, according to her teachers, she would never have managed previously. Improvements are noted by teachers, artists and pupils alike in attendance, engagement, attitudes to learning, relationships between pupils, and in specific curriculum skills/knowledge, particularly Maths and literacy. The video supports the 'transformative power of the arts' rhetoric of Creative Learning Through the Arts (Welsh Government, 2015), but it is not made explicit who the participants are, so it is not possible to determine whether these pupils are included in the project because they are considered to be 'disadvantaged', whether they are eFSM or MAT. However, the project does make clear its aims of changing behaviour and attitudes to learning, in addition to the curriculum and cross-curricular skills focus. Like the other Networks, Network D mirrors the rhetoric of Creative Learning through The Arts (Welsh Government, 2015) and advocates for the cross-curricular benefits of the arts, and for their capacity to raise standards, particularly in literacy and numeracy. However, the website also includes links to academic research articles detailing arts-based projects with mindfulness outcomes 
(Schonert-Reichl and Lawlor, 2010; See and Kokotsaki, 2015; Sharp, 2001). These references represent a shift away from the curriculum, skills, and potential economic benefits indicated in the Welsh Government's action plan.

The Arts and Wellbeing in Education Professional Learning Programme. Within Network D, a team of artist/educators grouped together to devise a self-contained series of four professional learning workshops for schools, called Arts and Wellbeing in Education (AWE) $)^{1}$. The team comprised three Arts Champions and a yoga instructor, and the programme included four workshop sessions, each focusing on a different art form and led by a different practitioner. The workshops were developed in response to requests from school staff, after an initial INSET day that included all the elements of the separate workshops as optional, carousel activities. The order of the sessions was, on occasion, adapted according to the needs of schools, and the programme comprised the following workshops: Introduction to the Network, funding opportunities, and a yoga and mindfulness session; Drawing with Mindfulness; Storytelling with Line: Clay and Plaster Casting; Mark-making with Sensory Stimuli and Calming Techniques. After a small number of schools requested the AWE programme, the Challenge Advisors at the Regional Consortium made recommendations for specific schools that they felt would benefit from participating. These were schools that were facing difficulties in a range of areas, such as Estyn Inspections that were cause for concern. The workshops were delivered as after school, 'twilight' sessions to enable participation without the need for arranging lesson cover. The aim of the programme was described at interview by

\footnotetext{
${ }^{1}$ Arts and Wellbeing in Education (AWE) is a pseudonym, to protect the anonymity of participants in line with the ethical approval for this research project.
} 
Catherine ${ }^{2}$, the unofficial 'leader' of the team, as supporting teachers by, "looking at where their interest in the creative arts started, and how they wanted to deliver that back into the classroom, in a holistic way." Catherine also described how this connected with the key benefit of the AWE programme as she saw it, and explained that, "the wellbeing aspect was really important as an element of this because it all sort of filtered across the sessions we were going to deliver." Both interviewees felt that, while there were skills and techniques that they could share in the sessions, the overall aim of the programme should be about "showing care" by giving teachers the opportunity to explore their own creativity and take time for themselves, and for each other. The hope was that this would have a knock-on, positive effect on the culture of the classroom - and wider school. Discussing their role in this process brought up some forceful opinions relating to the language used in the Welsh Government and Arts Council of Wales action plan. The team as a whole strongly rejected the term, 'Arts Champions' since they believed it established a hierarchy of expertise that they did not recognise, or find helpful. Rachel and Catherine, the two interviewees, also found the concept of 'creative learning' problematic in describing their practice. Despite wholehearted approval of Dai Smith's report, and in positive anticipation of the new, 'Donaldson' curriculum, they both rejected 'creative learning' as a meaningful concept since it implied classroom practice rather than any wider arts-based activities or creativity. They expressed concerns that the connotations of such language did not support teachers in developing their own creativity, and reinforced the barriers to accessing the possibilities of being creative, in the classroom or any other context.

\footnotetext{
${ }^{2}$ Throughout the article, the Arts Champions are referred to using pseudonyms, in line with the ethical approval received for this project.
} 
Returning to Foucault (1991) as a means to unpack this issue further, defining creativity solely in relation to classroom practice narrows its articulation, and the individual's experience. Referring to all forms of creativity within education as 'creative learning' can be understood as enforcing a homogeneity of expression which, by creating an expectation in terms of practice, thereby generates a norm. For a teacher to be considered creative according to this definition, it must be recognised in her classroom practice, and it must be measurable, otherwise how will we know whether she is creative, and to what extent. Individuals can be identified as performing according to a set of standards, judged, ranked, improved upon, and ultimately re-disciplined to enable conformity to expectations. A broader understanding of creativity, as advocated by the AWE team, allows for heterogeneous, multifaceted action and expression that moves beyond classroom practice to a wider conceptualisation of pedagogy, that can include but is not limited to/by a freedom of the individual. Of course, this relative freedom is not what a disciplinary system requires of an individual; it requires systematic identification of practices within a hierarchical structure. The freedom of expression and rejection of hierarchy encouraged and celebrated by Catherine, Rachel and Liz can be understood as an effect of power generated through the struggle over the benefits and value of creativity. In Foucauldian terms, the struggle to resist an education policy that defines creative learning in relation to curriculum objectives has produced a discourse of creativity that rejects any government-driven, politically motivated outcomes relating to raising standards and international league tables. Foucault defines discourse as "practices that systematically form the objects of which they speak" (Foucault, 2002a). The AWE 
discourse of creativity centres on the concepts of wellbeing and collaboration, which are considered to be benefits in and of themselves. In this context, the choice of defining, enacting, and learning/teaching creativity embodied by the AWE team, can be understood as producing this conceptualisation of creativity.

The benefits of the AWE professional learning programme were described by all three Arts Champions as providing support for teachers' wellbeing, particularly during a time of 'need' in the midst of school improvement initiatives; learning mindfulness techniques for pupils; and creativity, for both staff and pupils. The tone of the Mark-Making session I observed was characterised by an acceptance of the capacity of the arts generally to engender outcomes that fell within the broad scope of wellbeing, and, more specifically, for certain activities to generate certain emotional and behavioural responses. Practical examples were demonstrated by the session leader, such as using a 'mindful jar', 'breathing dragon' and a Hoberman Sphere, to teach children and young people relaxing breathing techniques, and to encourage quiet, calm time when they were feeling anxious, overwhelmed or if tempers ran high. Each of the artistic skills/techniques we learned was also carefully designed to encourage conversation about how the activities made us feel, and we were encouraged to consider how we felt about the main 'lesson' of the session, which was collaboration. Creativity was represented as an element of being human, rather than as a skill to be taught. It was explained that techniques could be learned, but that we are all creative, and this creativity can have other effects - on us as individuals, and on our place within a group. In this respect, the benefits of the arts were articulated in terms of our wellbeing, rather than in reference to curriculum objectives, or pupil outcomes. 
The other Arts Champions in the team also emphasised the artistic process. For example, during a Drawing with Mindfulness workshop, Liz, the session leader, spoke about creativity as an action in and of itself, rather than focusing on the end result. She told us that, "being creative is enough", and, intrinsic to the activity of creativity is the opportunity to quiet the mind of unhelpful, negative, or overwhelming thoughts. Despite the quiet approach, these bodies are not "docile"; they will not be "subjected, transformed and improved" by an agency external to the individual (Foucault, 1991: 136). This expression of the value of creativity exemplifies how in the AWE programme, control/power shifts from the political/educational system to the individual, since creativity is not used as a means to advocate any socio-political advantage beyond itself. The statement also implies the rejection of a normalizing judgement. Liz does not quantify creativity, nor does she set parameters for how it might be achieved, experienced, observed. There is no assessment of what it means to 'be creative', nor of the final, creative product within this programme that would establish a 'norm'; an expected level of attainment or achievement. AWE sidesteps any association between this creativity and, for example, improvements in literacy and numeracy advocated through the Welsh Government policy statements outlined in Creative Learning through the Arts (Welsh Government, 2015). Instead, the emphasis within AWE, as articulated in this instance by Liz, is on a more personalised sense of achievement, not measured against any hierarchical 'norms', but through our own, individual recognition of how we felt during the workshops. The statement that, "being creative is enough" exemplifies a resistance to the policy discipline that aims to exercise control by raising standards through creativity. This resistance highlights the existence of Welsh Government power 
over the body of teachers, and by extension pupils, but the bodies of the AWE programme are not 'docile'; they will not be put to use in the manner intended by Government.

The message that being creative was enough was not always accepted, however, and at times, there was a disconnect between the artists' aims, and the expectations of the school/staff. One session began with a staff room discussion regarding the need to include everyone in the school in a creative, arts project, without considering creative ways of doing so. It was understood that in order for the activity to be truly inclusive, every pupil should have equal access to equal experience. This perception then set off a train of conversation about the impossibility of such a task, given the difficulties in timetabling, staffing, and resourcing such an ambitious event. Staff were looking to the Network to deliver a one-off project that would meet curriculum/school objectives, and produce a piece of public art. Whereas, the AWE team were advocating for a different approach to inclusivity that is democratic in the sense of ensuring everyone is involved to whatever degree they are able, capable, interested. Through this programme, the Arts Champions advocated the benefits of the arts for social good, emphasising the personal over the political, and focusing on the value of creativity in and of itself, rather than in reference to an end product or pre-determined learning outcome - "being creative is enough".

The Regional Arts and Education Networks outline the benefits of the arts to curriculum education, either directly, through pupils' learning, or implied through the aims of 
professional learning opportunities. Each Network offers at least some examples of specific skills, knowledge, competencies that can be supported and improved through creative learning. However, unlike the Welsh Government / Arts Council Wales approach, none of the Networks make reference to the economy, or to industry. The case study Network, D, makes explicit claims for the benefits of creative learning in raising literacy and numeracy, which are illustrated and expanded upon in the project examples shared via the website. The Network D project descriptions also make claims for the potential for creative learning to improve pupil behaviour and attitudes to learning. These are not central aims of Creative Learning through the Arts (Welsh Government, 2015), but the claims mirror other literatures on the benefits of creative learning and the arts (for example, Ewing, 2010; Harland et al, 2000; Wagner, 2006). Where Network D diverges significantly from the Welsh Government rhetoric is through the repeated references to mindfulness and the focus on wellbeing as a benefit. This is evident through the shared resources on the member pages of the website, and made available via mailshot, and is extended in the case study professional learning programme, Arts and Wellbeing in Education (AWE). Network D moves away from any links to economic value to a more democratic approach, focusing on the possibilities of art for social good (Banaji et al, 2010).

AWE extends and concentrates the social perspective advocated by Network D. The programme combines learning in and learning through art that starts from the assumption of a positive impact on wellbeing, and avoids the pitfalls of elitism inherent in debates around the need for learning in particular art forms (Fleming, 2011). This was achieved 
by taking an inclusive approach to participation, and to creativity that rejected a

hierarchical approach to teaching and learning and encouraged shared practice. AWE also shifts away from attempting to map the benefits, and therefore the 'value', onto another subject, skill, or competency, and the Arts Champions did not concern themselves with the possible impact on attainment levels or curriculum-specific skills or competencies. This, they believed, should be left to the expertise of teachers since they know their own pupils and how best to support them in improving in whichever skills/competencies were required, 'because then you're doing the role that they should be doing, [and] there's absolutely no point in that" (Rachel). Instead, the value of AWE lay in its capacity to support teachers' wellbeing and to help remind teachers why they chose this profession, give them positive reinforcement, build their resilience, and allow this to have a knock-on effect on pupils. The value was thereby assumed to be social, emotional, personal, and judged by the participant rather than imposed by an external agent.

\section{Discussion and Implications}

The findings relating to the research question, how the benefits of Creative Learning through the Arts (Welsh Government, 2015) are articulated through a case study Arts and Education Network, reveal at least two useful insights that can inform future arts/education initiatives. These are that the benefits of arts education are multifarious and dependent on context; dispersal of power across local networks enables the arts to contribute to outcomes that are determined by, and therefore meaningful to, the learner, and disrupt politically motivated conceptualisations of value to allow for individualised experiences of creativity. First of all, tracing the practical and pedagogical response to 
Creative Learning through the Arts (Welsh Government, 2015), through the Regional Arts and Education Networks, to a case study professional learning programme within one of the Networks, highlights the evolving articulations of the benefits of the arts in education. The analysis of these articulations reveals a shift in their presumed value, from an economic perspective, based on skills acquisition, to one that centres on social and personal outcomes. Returning to Foucault, these shifts represent a dispersal of power across the Networks, and through individuals, as a range of agents determine who is to benefit from the arts, and what those benefits might comprise, set within a wider value system. Each Network claims positive outcomes for the arts, while remaining broadly within the parameters established by the Welsh Government and Arts Council of Wales. These comprise curriculum aims, such as improved literacy and numeracy, as well as behavioural and/or attitudinal 'benefits' that are valued by the teachers. The dispersal of power across the Networks establishes an environment of relative conformity to Welsh Government aims, with some local adaptation according to context, personal choice of Network personnel and/or available resources. Network D includes curriculum and Welsh Government Mission objectives, and also focuses on mindfulness and wellbeing, representing a diversion from the central aims of Creative Learning through the Arts (Welsh Government, 2015). While the Welsh Government/Arts Council of Wales objectives can be interpreted as advocating positive social outcomes, Network D makes this advocacy more explicit. The selection of resources and focus of workshops highlight the belief in the potential of the arts to contribute to social outcomes, including wellbeing and mindfulness, while maintaining the classroom focus. Within this environment, the AWE programme can be understood as a local revolution. AWE disrupts the 
transformative power of the arts from economic imperative and direct curriculum objectives to a social good that is self-defined rather than imposed. In this example, the Arts Champions elected not to teach the teachers about pedagogies, and instead chose to engage them in creative practice, allowing space for the teachers to develop their own ideas about classroom practice based on their experience and the needs of the pupils. Power in AWE is therefore placed in the hands of the participants. Pupils were taken into consideration but not objectified in order to bring about improvement - in their 'performance' or that of the school. The AWE programme suggests that it is possible to hand control over to the learners and allow her/him to determine her/his own benefits from the arts and creativity, and assign value according to her/his needs, rather than imposing a pre-determined benefit conforming to an assumed value on a whole school/region/nation.

In drawing out the shifts in articulations of the benefits of the arts in and to education through these case study examples, this article contributes to debates around the perceived benefits of the arts, and shows that policy level articulations can be disrupted and transformed at local level, where context exerts a greater force than political will. In order to increase the strength of evidence and assert a more generalisable conclusion, more research is needed into how these benefits are perceived by learners/participants in order to ascertain whether the intended benefits/outcomes are felt in practice. Comparison with professional learning programmes in other Networks across Wales, and in other global, curriculum contexts would also be useful in enabling wider discussion around professional learning in the arts. However, the findings and discussion offered here point 
to the need for consideration of how the benefits of the arts are articulated, for whom, and the values that inform and are communicated through these choices. This is particularly relevant during a time of educational change in Wales, when the Expressive Arts become an integral element of the new curriculum, and professional learning is undergoing a radical shift through the National Mission in education.

\section{Funding}

The author received no financial support for the research, authorship, and/or publication of this article.

\section{References}

Banaji S (2011) Mapping the rhetorics of creativity. In: Sefton-Green J, Thomson P, Jones K and Bresler L (eds) The Routledge International Handbook of Creative Learning. London: Routledge, pp. 36-44.

Banaji S, Burn A and Buckingham D (2010) The Rhetorics of creativity: A Literature Review. $2^{\text {nd }}$ Edition. Newcastle: Creativity, Culture and Education Series.

Belfiore E (2011) The 'Transformative Power' of the Arts. In: Sefton-Green J, Thomson P, Jones K and Bresler L (eds) The Routledge International Handbook of Creative Learning. London: Routledge, pp. 27-35.

Bogdan RG and Biklen SK (1992) Qualitative Research for Education (second edition). Boston, MA: Allyn and Bacon. 
Carr W and Hartnett A (1996) Education and the Struggle for Democracy. The Politics of Educational Ideas. Buckingham: Open University Press.

Cultural Learning Alliance (2011) Key research findings: The case for cultural learning. London: Cultural Learning Alliance.

Donaldson G (2015) Successful Futures: Independent Review of Curriculum and Assessment Arrangements in Wales. Cardiff: Welsh Government.

Drotner K (2011) The Cult of Creativity. Opposition, incorporation, transformation. In: Sefton-Green J, Thomson P, Jones K and Bresler L (eds) The Routledge International Handbook of Creative Learning. London: Routledge, pp. 72-80.

EACEA (2009) Arts and Cultural Education at School in Europe. Brussels: Education, Audiovisual and Culture Executive Agency.

Estyn (2015) Best Practice in Teaching and Learning in the Creative Arts at Key Stage 2. Cardiff: Estyn

Ewing R (2010) The Arts and Australian Education: Realising potential. Camberwell, Victoria: Australian Council for Educational Research.

Fleming M (2011) Learning in and through the arts. In: Sefton-Green J, Thomson P, Jones $\mathrm{K}$ and Bresler L (eds) The Routledge International Handbook of Creative Learning. London: Routledge, pp.177-185.

Foucault M (1980) Power/Knowledge. Selected Interviews and Other Writings 19721977. Edited by Colin Gordon. London: Harvester Press.

Foucault M (1991) Discipline and Punish. The Birth of the Prison. London: Penguin Books. 
Foucault M (2002a) The Archaeology of Knowledge. Translated by A.M. Sheridan Smith. London: Routledge Classics.

Foucault M (2002b) The Order of Things. An Archaeology of the Human Sciences. London: Routledge Classics.

Harland J, Kinder K, Lord P, Stott A, Shagen P and Haynes J (2000) Arts Education in Secondary Schools: Effects and Effectiveness. Slough, Berkshire: NFER.

Henley D (2012) Cultural Education in England. London: DCMS/DfE.

Jeffries B (2018) Creative subjects being squeezed, schools tell BBC. BBC News. 30

January 2018. Available at: http://www.bbc.co.uk/news/education-42862996 (Accessed 2 February 2018).

LeCompte M and Preissle J (1993) Ethnography and Qualitative Design in Educational Research (second edition). London: Academic Press.

Mowlah A, Niblett V, Blackburn J, Harris M (2014) The Value of Arts and Culture to People in Society. An Evidence Review. Manchester: Arts Council England.

NACCCE (1999) All Our Futures: Creativity, Culture and Education. Sudbury, Suffolk: DfEE Publications.

Nichols B (2010) Introduction to Documentary. 2nd Edition. Bloomington, Indiana: Indiana University Press.

Ruppert SS (2006) Critical Evidence. How the ARTS Benefit Student Achievement. Washington DC: National Assembly of State Arts Agencies.

Schonert-Reichl KA and Lawlor MS (2010) The effects of a mindfulness-based education program on pre- and early-adolescents' well-being and social and emotional competence. Mindfulness 1: 137-151. 
See BH and Kokotsaki D (2015) Impact of arts education on the cognitive and noncognitive outcomes of school-aged children. A review of evidence. Durham: Education Endowment Foundation.

Sharp C (2001) Developing young children's creativity through the arts: what does research have to offer? London: National Foundation for Educational Research.

Smith D (2013) An Independent Report for the Welsh Government into Arts in Education in the Schools of Wales. Cardiff: Welsh Government.

Spencer E, Lucas B, and Claxton G (2012) Progression in Creativity: Developing new forms of assessment. Final Research Report. Newcastle: CCE.

Spradley JP (1980) Participant Observation. New York: Holt, Rinehart and Winston. Wagner T (2006) Building Creative Capacities for the 21 st Century. Lisbon: UNESCO. Warwick Commission (2015) Enriching Britain: Culture, Creativity and Growth. The 2015 Report by the Warwick Commission on the Future of Cultural Value. Available at: https://warwick.ac.uk/research/warwickcommission/futureculture/finalreport/warwi ck_commission_final_report.pdf (Accessed 20 October 2017).

Welsh Government (2013) The Welsh Government response to Professor Dai Smith's Report on: 'Arts in Education in the Schools of Wales'. Available at: https://beta.gov.wales/sites/default/files/publications/2018-02/the-welshgovernment-response-to-professor-dai-smithss-report-on-arts-in-education-in-theschools-of-wales.pdf (Accessed 21 august 2018).

Welsh Government (2015) Creative Learning through the Arts: An Action Plan for Wales. Available at: http://www.artswales.org.uk/c_engagement-and- 
participation/action-plan-creative-learning-through-the-arts (Accessed 17 April 2015).

Welsh Government (2017) Education in Wales: Our national mission. Action Plan 201721. Available at: http://gov.wales/docs/dcells/publications/170926-education-inwales-en.pdf (Accessed 2 February 2018).

Winner E, Goldstein T and Vincent-Lancrin S (2013) Arts for Arts' Sake? The Impact of Arts Education. OECD Publishing: Educational Research and Innovation. 